\title{
The transverse-vertical incision (Alazzam hybrid incision)
}

\author{
Moiad Alazzam ${ }^{1}(1) \cdot$ Mostafa Abdallah Khalifa ${ }^{2} \cdot$ Abdallah Al-Ani $^{3}(0)$
}

Received: 21 December 2020 / Accepted: 3 December 2021 / Published online: 23 January 2022

(c) Crown 2021

\begin{abstract}
Open abdominal surgery evolved around two incisions, vertical and transverse incisions. Transverse incisions are associated with less postoperative morbidities but offer limited access. Vertical incisions offer better access but are associated with more complications. We describe here a hybrid incision, transverse-vertical incision that offers adequate exposure for complex lower abdominopelvic surgery while overcoming the limitations and morbidities associated with midline and transverse incisions.
\end{abstract}

Keywords Vertical incision, $\cdot$ Transverse incision, $\cdot$ Maylard, $\cdot$ Midline incision, $\cdot$ Abdominopelvic surgery

\section{Background}

Abdominal surgery is an essential component for healthcare and requires a significant proportion of hospital resources. Although laparoscopy/robotic procedures are becoming more popular, still a significant proportion, particularly the larger, more complex procedures, are performed by open technique[1]. Surgical access to the abdomen and pelvis can be achieved through multiple incision types, which can be broadly divided into either midline, including paramedian, or transverse, including oblique[2].

The type of abdominal incision can influence multiple outcomes. In practice, the choice of incision is usually based on the surgeon's preference rather than the patient's criteria. For the surgeon, ease of access, time to open and close the abdomen, and incidence of postoperative complications such as hernia and delayed recovery are important. For the patient, pain, cosmetic appearances, and rapid return to normal function are important. Economically the duration of operation and duration of hospital stay determine cost $[2,3]$.

Moiad Alazzam

m.alazzam@nhs.net

1 Consultant Gynaecological Oncology Surgeon, Department of Gynaecological Oncology, Churchill Hospital-Oxford University Hospitals, Old Road, Oxford Headington OX3 7LN, UK

2 Department of Gynaecological Oncology, Fellow in Gynaecological Oncology, Oxford, UK

3 School of Medicine, Jordan University, Amman, Jordan
The publication of the LACC trial intensified the debate of what is the best surgical approach for women diagnosed with early-stage cervical cancer[4]. Herein, we describe a step-by-step hybrid transverse-vertical incision, Alazzam hybrid incision which retains the benefits of both transverse and midline incisions (Fig. 1). To our knowledge, this incision has not been described to date.

\section{Alazzam hybrid incision—step by step}

The patient is placed in a modified lithotomy position. After cleaning the abdomen and draping the patient, the abdomen is opened using an Alazzam hybrid incision as described below:

(1) Identification of anatomical landmarks (Fig. 2)

a. Upper lateral incision borders: a mark is made $2 \mathrm{~cm}$ medio-cephalad to the anterior superior iliac spine (ASIS) on each side.

b. A third mark is made $3-5 \mathrm{~cm}$ in the midline above the upper border of the symphysis pubis.

c. A curved line is drawn with the convexity toward symphysis pubis with a curve of a small radius circle.

(2) Incision for the outer layers (Fig. 3)

a. Skin is incised along the curved line drawn either with cutting diathermy needle or surgical scalpel and fat layer opened in a routine manner. 
Fig. 1 General view of the incision; landmarks, transverse, and vertical incisions
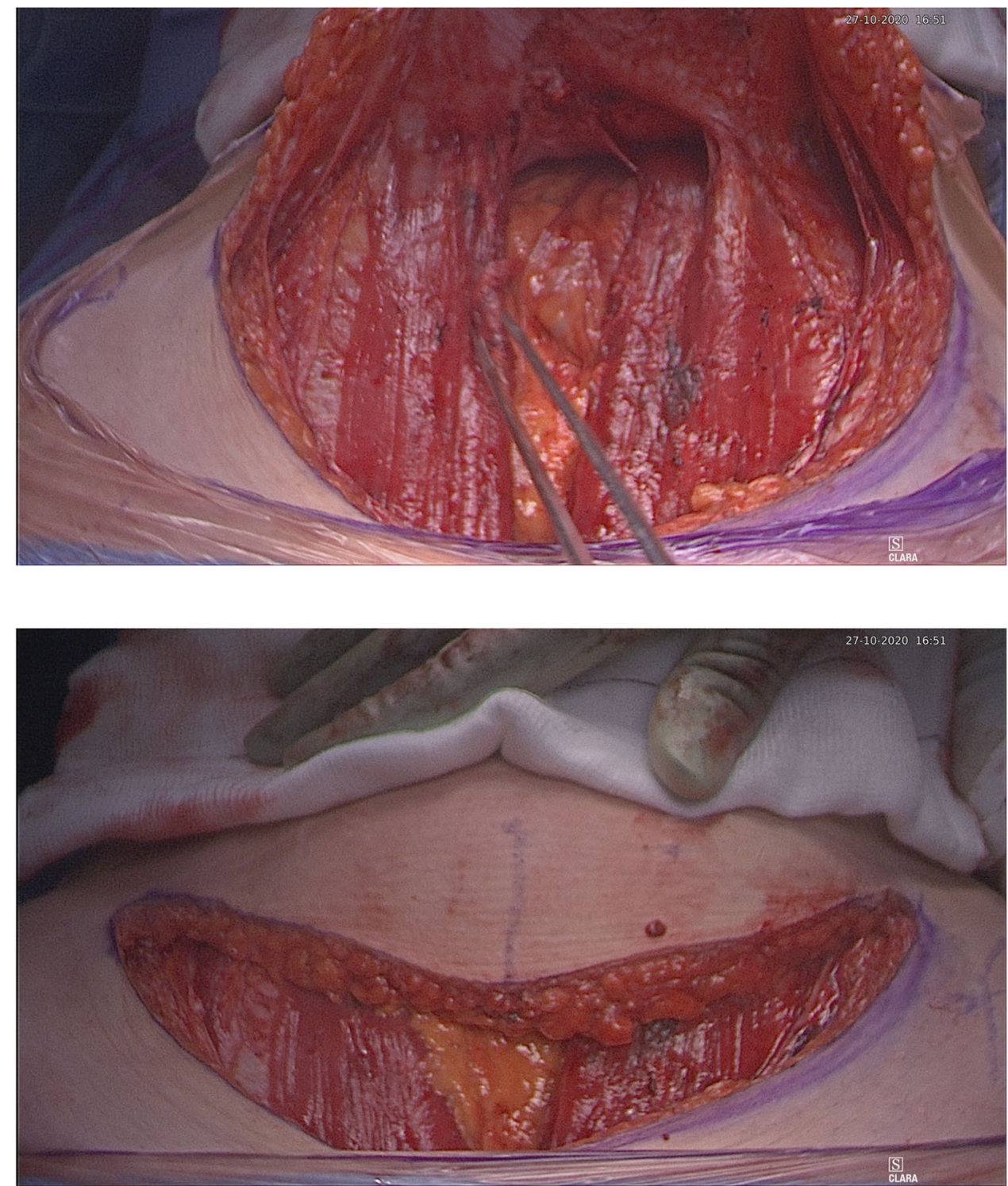

Fig. 2 Skin and bone landmarks

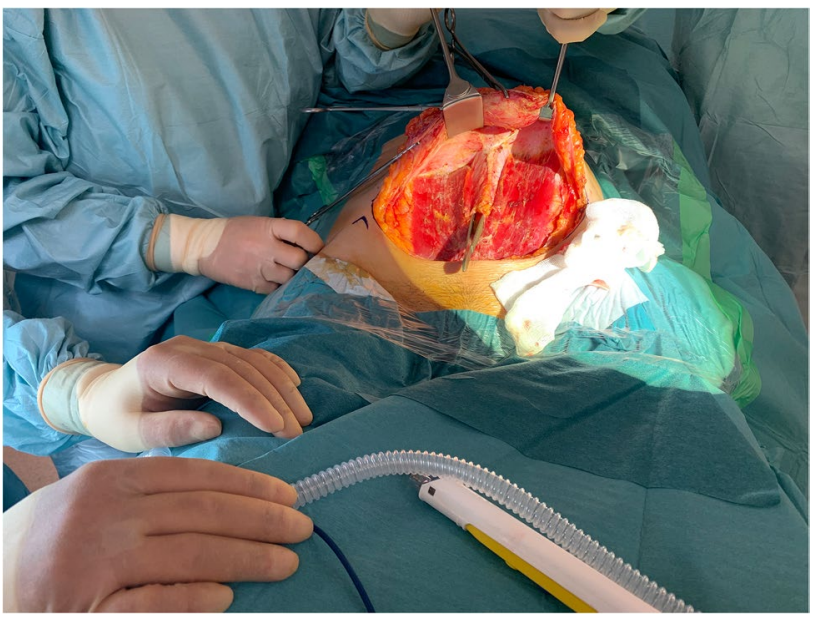

Fig. 3 Exposure after completion of anterior rectus sheath leaf transverse dissection b. The outer leaf of the rectus sheath is opened (transversely) mirroring the shape of the skin incision.

c. The anterior surface of the rectus muscles carefully dissected off the posterior wall of the outer rectus sheath leaf up to the level of the umbilicus centrally and to the level of the incision margins laterally.

d. The rectus muscles carefully dissected off the anterior surface of the inner rectus sheath leaf extending up to $2 \mathrm{~cm}$ above the level of the umbilicus

(3) Vertical incision (Fig. 4)

a. The inner rectus sheath layer (midline) is divided starting from the arcuate ligament and extending up to the umbilicus. 
Fig. 4 Exposure after completion of posterior rectus sheath leaf vertical dissection

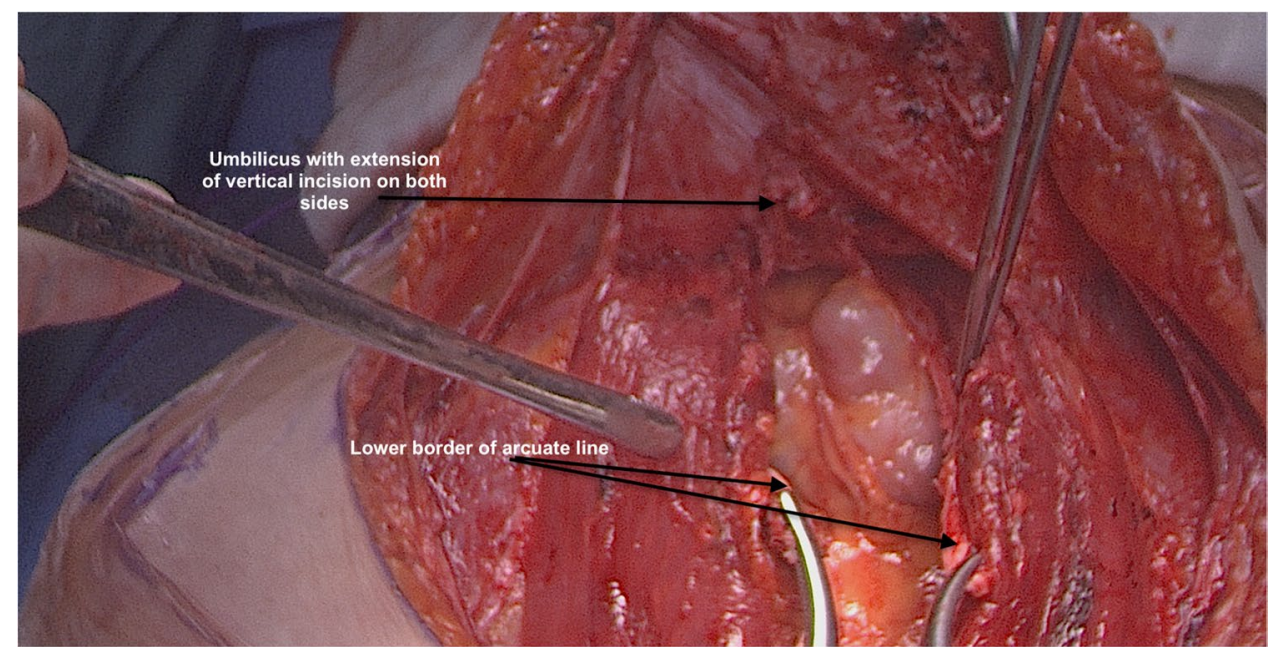

b. If further extension is needed, then the inner rectus sheath can be divided on either side of the umbilicus.

\section{(4) Closure (Fig. 5)}

a. The inner leaf of the rectus sheath is closed with interrupted monofilament suture (we use PDS \#1). We normally start from the upper angle until the arcuate line. (Fig. 5).

b. The outer leaf of the rectus sheath is closed transversally with continuous suture using Loop PDS with alternating simple interrupted sutures to decrease tension and risk of hernia.

c. Skin is normally closed subcutaneous with $3 / 0$ Monocryl (Figs. 64 weeks post-surgery).

\section{Methods and materials}

Following the publication of the LACC trial in 2018 and the subsequent changes to surgical approach in particular cervical cancer, Alazzam hybrid incision was introduced in mid-2020 with the aim to overcome the potential morbidities from the midline and Maylard incisions.

We prospectively recorded the data for all patients who underwent radical pelvic surgery using "Alazzam hybrid incision". Extracted data included age, BMI, total operating time, intraoperative complications, immediate and delayed postoperative complications, use of analgesia, and incidence of hernia.

Between May 2020 and April 2021 (Table 1); 12 patients underwent primary radical pelvic surgery using Alazzam hybrid incision, 11 had stage 1 cervical cancer, two patients had radical trachelectomy, and nine radical abdominal

Fig. 5 Closure of rectus sheath posterior leaf

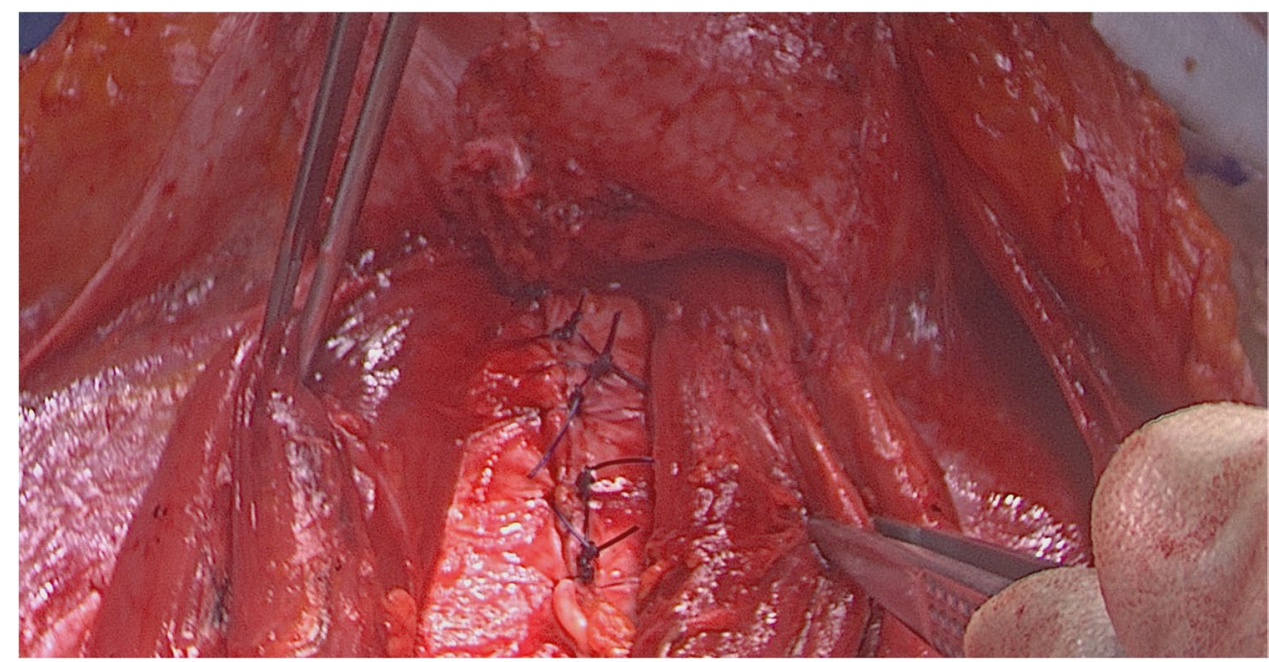




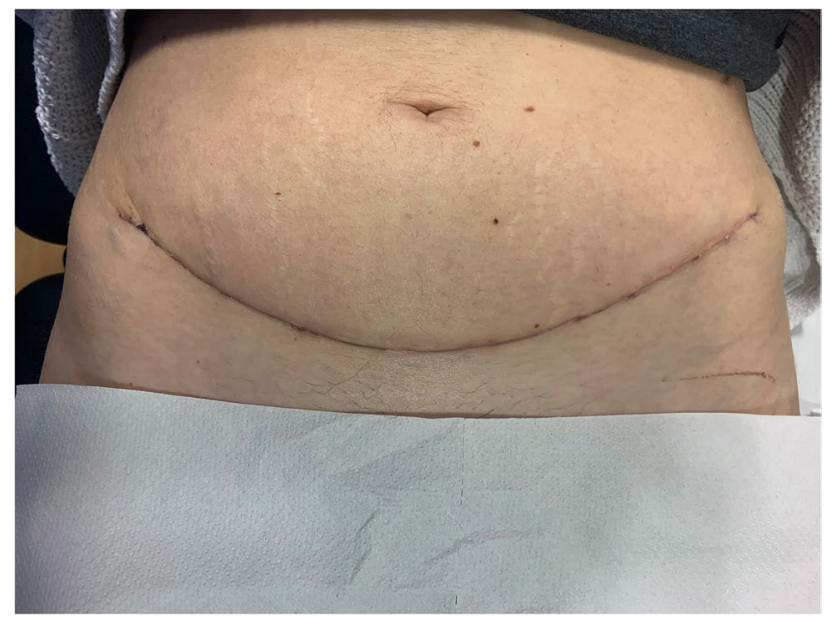

Fig. 6 Appearance of skin 4 weeks post-surgery

hysterectomies. Patients were followed up until October 2021. The 12th patient had the surgery for high-grade endometrial cancer. In all patients, bilateral pelvic lymphadenectomy was performed. The surgery was completed successfully in all patients without any need for extension or midline conversion. None of the patients had any significant intraoperative complications. The average blood loss was $409 \mathrm{ml}$. Postoperatively, the pain was well controlled-paracetamol only $(n=4)$, paracetamol, and as required codeine or ibuprofen $(n=8)$. There was no reported hernia in all patients. There were no reported long-term complications during the follow-up period.

\section{Discussion}

The success of abdominopelvic surgeries is dependent on a variety of factors, including the type of incision, site of incision, adequacy of exposure, and optimal closure[5].
Table 1 Study cohort outcomes using Alazzam hybrid incision

\begin{tabular}{ll}
\hline Characteristics & AHI $(n=12)$ \\
\hline Body mass index, median (IQR) & $29.14(8.7)$ \\
Estimated blood loss, median (IQR) & $409(317)$ \\
Length of surgery (min), median (IQR) & $296.3(36.1)$ \\
Hospital stay (day), median(IQR) & $5(1)$ \\
Conversion to midline & 0 \\
Ureteric injury & 0 \\
Accidental bladder/bowel injury & 0 \\
Hernia & 0 \\
Admission to ITU & 0 \\
Return to theatre $<24 \mathrm{~h}$ & 0 \\
\hline
\end{tabular}

Furthermore, surgery is increasingly being utilized in highrisk patients with multiple concomitant comorbidities [6]. Therefore, it is of vital importance to consider the safety of procedures while ensuring the overall efficacy in terms of postoperative recoveries, such as immediate pain relief and/ or pulmonary function.

The choice of incision is contingent on a myriad of factors, including the adequacy of site exposure, dissemination pattern of malignancy, presence of extra-pelvic metastasis, presence of obesity, and patient's cosmetic considerations [7]. Albeit, the choice of incision is frequently based on the surgeon's own preference and expertise rather than any patient or economic considerations [2]. Throughout the literature, abdominopelvic surgeries were reported to be conducted using three different types of incisions including midline vertical incisions, suprapubic transverse incisions (i.e., Pfannenstiel, Maylard, and Cherney), and infra/ supraumbilical incisions [8], each of which is associated with a different profile of surgical advantages and postoperative complications.
Fig. 7 Adequacy of operating surgical field exposure

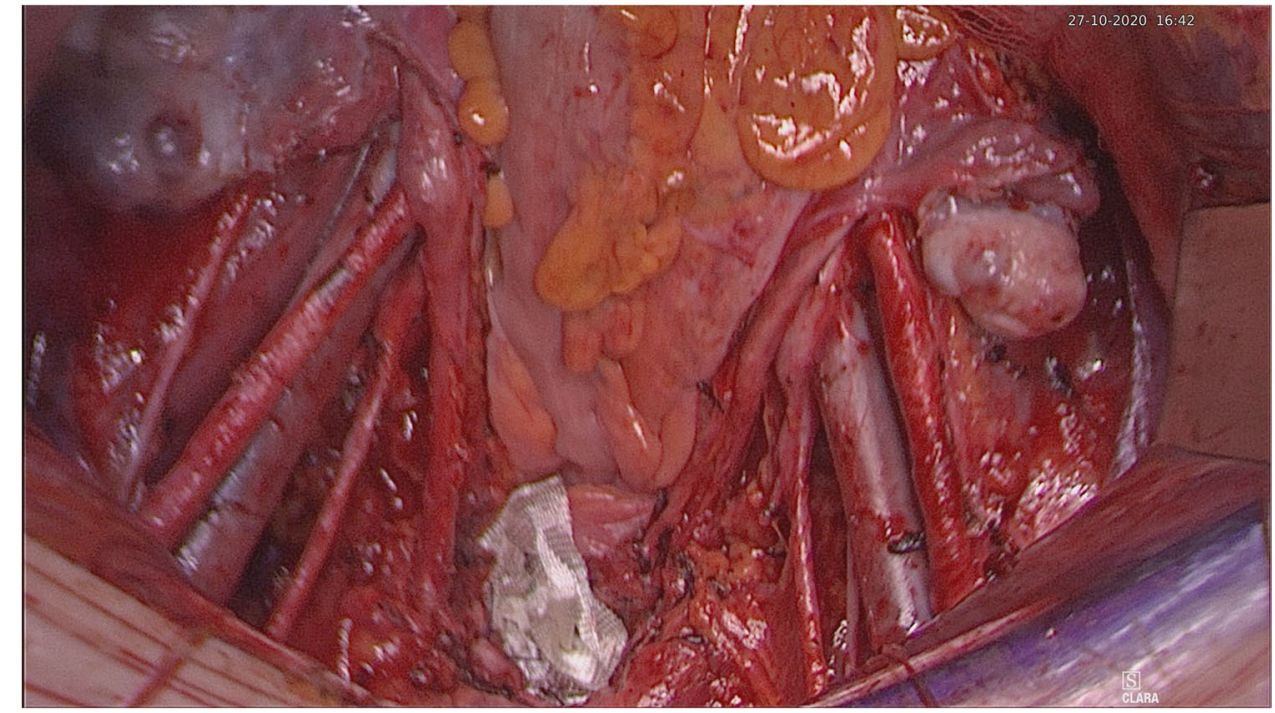


Midline incisions are almost exclusively used in gynecologic cancer surgery as it allows quick entry into the abdominal cavity with minimal blood loss and can be easily extended depending on intraoperative findings [9]. However, these incisions are associated with inadequate cosmetic results and are coupled with complications such as wound dehiscence, incisional hernias, and pulmonary deterioration [10-12]. These complications may result from the presence of an avascular wound bed which hinders wound healing, and the burden of tension on wound closure resulting from the contralateral contraction of abdominal muscles perpendicular to the incision's direction[12, 13]. Due to the perpendicular nature of vertical/midline incisions with reference to the oblique muscle layer, it cuts medial to they might be associated with more pain due to nerve damage as nerves run in a parallel fashion to the oblique muscle layer crossing the midline. Bickenbach et al. (2013) conducted a meta-analysis on all randomized trials reporting on incision types and demonstrated significantly higher narcotic use in patients undergoing midline incisions further fortifying the aforementioned statements [12].

On the other hand, transverse techniques are associated with superior outcomes in terms of cosmetics, wound healing, the incidence rate of incisional hernia, wound strength, and interferes less with postoperative respiration [7, 9, 12]. However, their disadvantages include intense hemorrhage, abdominal nerve injury, and is more time consuming [7]. Transverse incisions' greatest limitation is its limited exposure into the abdominal cavity, which renders the entire incisional technique as a second-choice modality, particularly in radical hysterectomies and pelvic lymph node dissections [10]. While both the Cherney and Maylard incisions act as a feasible alternative to midline laparotomy due to increased pelvic exposure [14], the Cherney incision is twice as fast with an average completion time of 1 to $2 \mathrm{~min}$, spares the inferior epigastric resulting in less bleeding and hematoma formation, and is muscle "separating" as it cuts parallel to the rectus muscle fibers providing greater wound strength [3]. On the other hand, Maylard incisions, despite being

Table 2 Summary the various common incisions

\begin{tabular}{|c|c|c|c|c|}
\hline Name of the incision & Measurement & Muscle cutting & Advantages & Disadvantages \\
\hline Midline (median) incision & $\begin{array}{l}\text { Can be extended depending } \\
\text { on required exposure }\end{array}$ & No & $\begin{array}{l}\text { Excellent exposure } \\
\text { Easily extendable } \\
\text { Minimum nerve damage } \\
\text { Rapid entry to abdomen }\end{array}$ & $\begin{array}{l}\text { Pain } \\
\text { Hernia } \\
\text { Poor cosmetic outcome }\end{array}$ \\
\hline Paramedian incision & $\begin{array}{l}\text { Can be extended depending } \\
\text { on required exposure }\end{array}$ & Yes & Same as median incision & $\begin{array}{l}\text { Higher infection rates } \\
\text { Hemorrhage } \\
\text { Longer operative time }\end{array}$ \\
\hline Pfannenstiel incision & $\begin{array}{l}10-15 \mathrm{~cm} \text { long and } 2 \mathrm{~cm} \\
\text { above the pubic sym- } \\
\text { physis }\end{array}$ & $\begin{array}{l}\text { No (can be used to widen } \\
\text { the incision) }\end{array}$ & $\begin{array}{l}\text { Better cosmetic appear- } \\
\text { ance } \\
\text { Less pain } \\
\text { Less interference with } \\
\text { postoperative respira- } \\
\text { tions } \\
\text { Greater strength }\end{array}$ & $\begin{array}{l}\text { Limited access to upper } \\
\text { abdomen and pelvic } \\
\text { sidewall } \\
\text { Hematomas } \\
\text { Poor exposure }\end{array}$ \\
\hline Joel-Cohen incision & $\begin{array}{l}10-12 \mathrm{~cm} \text { long } 3-5 \mathrm{~cm} \\
\text { above pubic symphysis }\end{array}$ & No & Same as Pfannenstiel & $\begin{array}{l}\text { Limited access to upper } \\
\text { abdomen and pelvic } \\
\text { sidewall } \\
\text { Hematomas } \\
\text { Poor exposure }\end{array}$ \\
\hline Cherney incision & $\begin{array}{l}2 \mathrm{~cm} \text { above the umbilicus. } \\
\text { Can extend to the level } \\
\text { of anterior superior iliac } \\
\text { spine }\end{array}$ & $\begin{array}{l}\text { Yes (a tendon detaching } \\
\text { incision) }\end{array}$ & $\begin{array}{l}\text { Same as Pfannenstiel } \\
\text { Access to pelvic sidewall }\end{array}$ & $\begin{array}{l}\text { Hematomas (lower risk than } \\
\text { Maylard) } \\
\text { Myonecrosis } \\
\text { Osteomyelitis } \\
\text { Limited access to upper } \\
\text { abdomen }\end{array}$ \\
\hline Maylard incision & $\begin{array}{l}4 \mathrm{~cm} \text { above the symphysis } \\
\text { pubis and extended later- } \\
\text { ally until } 3 \mathrm{~cm} \text { from the } \\
\text { anterior superior iliac } \\
\text { spine }\end{array}$ & Yes & $\begin{array}{l}\text { Same as Pfannenstiel } \\
\text { Access to pelvic sidewall }\end{array}$ & $\begin{array}{l}\text { Impaired circulation in the } \\
\text { lower extremity } \\
\text { Hematomas } \\
\text { Limited access to upper } \\
\text { abdomen }\end{array}$ \\
\hline $\begin{array}{l}\text { Alazzam hybrid incision } \\
\text { (described in this paper) }\end{array}$ & $\begin{array}{l}3 \mathrm{~cm} \text { above symphysis } \\
\text { pubis extending laterally } \\
\text { to } 2 \mathrm{~cm} \text { medial and above } \\
\text { ASIS }\end{array}$ & No & $\begin{array}{l}\text { Same as Pfannenstiel and } \\
\text { low midline incision } \\
\text { Access to pelvic sidewall } \\
\text { and abdomen below } \\
\text { kidney }\end{array}$ & $\begin{array}{l}\text { Time to enter abdomen (not } \\
\text { suitable for emergency) } \\
\text { Limited access to upper } \\
\text { abdomen }\end{array}$ \\
\hline
\end{tabular}


muscle cutting, retain the advanced of transverse incisions and are considered a suitable alternative to laparoscopy and in women with cervical cancer and complex pelvic conditions due to its excellent exposure of the pelvic sidewalls [15].

The Alazzam hybrid incision retains the advantages associated with both transverse and midline incisions while avoiding their inherent limitations. The incision is a muscle separating procedure that does not attempt to ligate the inferior epigastric vessels. Therefore, it retains the benefits of a Cherney incision, being muscle separating, while its avoidance of manipulating the inferior epigastric vessels contributes to less bleeding, less hematoma and neuroma formation, and maintains the vascularity of the rectus muscle and the wound bed underneath. Similar to a Pfannenstiel incision, the Alazzam hybrid incision does not impact pulmonary function and results in an optimal cosmetic result. Due to its muscle splitting nature, the Alazzam hybrid incision contributes to less pain on deep breathing, which enables it to avoid affecting the patient's ventilatory capacity, as historically documented [16, 17]. Moreover, the incision does not require a steep learning curve retaining both pace and operational simplicity compared to laparoscopic techniques which require experience and technological setup [7, 18]. The Alazzam hybrid incision's greatest strength and potential lie in its ability to provide adequate exposure, comparable to that of midline incisions, to the abdominopelvic cavity without any major compromises in terms of neither morbidity nor mortality. Therefore, the incision is suitable for pelvic and lower abdominal procedures (Table 2) (Figs. 6 and 7).

Nonetheless, the Alazzam hybrid incision's most significant limitation lies in its time to completion. The technique incorporates two different incisional types at different tissue levels of the abdominopelvic plane. Moreover, appropriate suturing and wound closure at two consecutive perpendicular angles partially contribute to increasing the overall length of the entire operation. Such limitation may theoretically predispose the technique to be associated with more complications, including but not limited to wound infections, surgical site infections, or venous thrombosis [19]. However, such theoretical risk is highly unlikely to be of significance since it would require the incision to prolong the duration of operation in a magnitude of hours and not mere minutes.

\section{Conclusion}

The evidence generated by the Laparoscopic Approach to Cervical Cancer (LACC) trial demonstrates that minimally invasive surgery results in lower rates of survival in patients with early-stage cervical cancer compared to its open abdominal counterpart [4]. As a result, a thorough understanding of different incision types or the development of superior techniques is of utmost importance considering the evidence-based return of open techniques for cervical cancer. While midline incisions are preferred in emergency and exploratory surgeries due to their ease, speed, and excellent exposure, they are associated with significant morbidity. The Alazzam hybrid incision presents itself as a feasible alternative to midline incisions as they provide surgeons, irrespective of the level of experience, with a fast and functional technique with minimal postoperative morbidity.

Availability of data and material The authors confirm they will provide data if required.

\section{Declarations}

Ethics approval This article does not contain any studies with human participants or animals performed by any of the authors.

Informed consent Informsed consent was obtained from all individual participants included in the study.

Consent for publication All participants included in the study consented for publication

Conflict of interest The authors declare no conflict of interests.

Open Access This article is licensed under a Creative Commons Attribution 4.0 International License, which permits use, sharing, adaptation, distribution and reproduction in any medium or format, as long as you give appropriate credit to the original author(s) and the source, provide a link to the Creative Commons licence, and indicate if changes were made. The images or other third party material in this article are included in the article's Creative Commons licence, unless indicated otherwise in a credit line to the material. If material is not included in the article's Creative Commons licence and your intended use is not permitted by statutory regulation or exceeds the permitted use, you will need to obtain permission directly from the copyright holder. To view a copy of this licence, visit http://creativecommons.org/licenses/by/4.0/.

\section{References}

1. Sajid MS, Bokhari SA, Mallick AS et al (2009) Laparoscopic versus open repair of incisional/ventral hernia: a meta-analysis. Am J Surg 197:64-72. https://doi.org/10.1016/j.amjsurg.2007.12. 051

2. Brown SR, Tiernan J (2005) Transverse verses midline incisions for abdominal surgery. Cochrane Database Syst Rev (4). https:// doi.org/10.1002/14651858.CD005199.pub2

3. Brand E (1991) The Cherney incision for gynecologic cancer. Am J Obstet Gynecol 165:235. https://doi.org/10.1016/0002-9378(91) 90259-t

4. Ramirez PT, Frumovitz M, Pareja R et al (2018) Minimally invasive versus abdominal radical hysterectomy for cervical cancer. $\mathrm{N}$ Engl J Med 379:1895-1904. https://doi.org/10.1056/nejmoa1806 395 
5. Fischer JE, Bland KI, Callery MP et al. (eds) (2007) Mastery of surgery, 5th edn. Lippincott Williams \& Wilkins, Philadelphia

6. Massarweh NN, Legner VJ, Symons RG et al (2009) Impact of advancing age on abdominal surgical outcomes. Arch Surg 144:1108-1114. https://doi.org/10.1001/archsurg.2009.204

7. Ayhan A, Dursun P, Gultekin M, Yuce K (2007) Comparison of midline and Pfannenstiel incision for radical hysterectomy with pelvic and paraaortic lymphadenectomy in cervical carcinoma. $\mathbf{J}$ Obstet Gynaecol Res 33:161-165. https://doi.org/10.1111/j.14470756.2007.00501.x

8. Croff W (1975) Transverse abdominal incisions in gynecologic surgery. J A0A 75:195-198

9. Walters M, Barber M (eds) (2010) Hysterectomy for benign disease. Elsevier Health Sciences

10. Lee SH, Yim GW, Lee DW et al (2008) Comparison of modified Cherney incision and vertical midline incision for management of early stage cervical cancer. J Gynecol Oncol 19:246. https://doi. org/10.3802/jgo.2008.19.4.246

11. Walming S, Angenete E, Block M et al (2017) Retrospective review of risk factors for surgical wound dehiscence and incisional hernia. BMC Surg 17:1-6. https://doi.org/10.1186/ s12893-017-0207-0

12. Bickenbach KA, Karanicolas PJ, Ammori JB et al (2013) Up and down or side to side? A systematic review and meta-analysis examining the impact of incision on outcomes after abdominal surgery. Am J Surg 206:400-409. https://doi.org/10.1016/j.amjsu rg.2012.11.008

13. Burger JWA, Van 't RietJeekel MJ (2002) Abdominal incisions: techniques and postoperative complications. Scand J Surg 91:315321. https://doi.org/10.1177/145749690209100401
14. Skolnik E, Miazga E, Zakhari A et al (2021) Beyond the Pfannenstiel: minimally invasive laparotomy incisions for maximum exposure. J Obstet Gynaecol Can 43:368. https://doi.org/10. 1016/j.jogc.2020.10.013

15. Ortiz Molina E, Díaz De La Noval B, Rodríguez Suárez MJ et al (2020) Maylard's incision: how to make an easy incision for complex pelvic abdominal surgery. Int J Gynecol Cancer 30:154-155. https://doi.org/10.1136/ijgc-2019-000876

16. Greenall MJ, Evans M, Pollock AV (1980) Midline or transverse laparotomy? A random controlled clinical trial. Part II: Influence on postoperative pulmonary complications. Br J Surg 67:191-194. https://doi.org/10.1002/bjs.1800670309

17. Lacy PD, Burke PE, O'Regan M et al (1994) The comparison of type of incision for transperitoneal abdominal aortic surgery based on postoperative respiratory complications and morbidity. Eur J Vasc Surg 8:52-55. https://doi.org/10.1016/S0950-821X(05) 80120-3

18. Spirtos NM, Eisenkop SM, Schlaerth JB, Ballon SC (2002) Laparoscopic radical hysterectomy (type III) with aortic and pelvic lymphadenectomy in patients with stage I cervical cancer: surgical morbidity and intermediate follow-up. Am J Obstet Gynecol 187:340-348. https://doi.org/10.1067/mob.2002.123035

19. Cheng H, Clymer JW, Po-Han Chen B et al (2018) Prolonged operative duration is associated with complications: a systematic review and meta-analysis. J Surg Res 229:134-144. https://doi. org/10.1016/j.jss.2018.03.022

Publisher's Note Springer Nature remains neutral with regard to jurisdictional claims in published maps and institutional affiliations. 